\title{
Vegetative nitrogen stress decreases lodging risk and increases yield of irrigated spring wheat in the subtropics
}

\author{
A. S. Peake $\mathrm{A}, \mathrm{E}, \mathrm{F}$, K. L. Bell ${ }^{\mathrm{B}}$, P. S. Carberry ${ }^{\mathrm{C}}$, N. Poole ${ }^{\mathrm{D}}$, and S. R. Raine ${ }^{\mathrm{E}}$ \\ ${ }^{A}$ CSIRO Agriculture, PO Box 102, Toowoomba, Qld 4350, Australia. \\ ${ }^{B}$ Queensland Department of Agriculture and Forestry, PO Box 102, Toowoomba, Qld 4350, Australia. \\ CICRISAT, Patancheru, Hyderabad, Telangana 502324, India. \\ ${ }^{D}$ Foundation for Arable Research, 23 High Street, Inverleigh, Vic. 3321, Australia. \\ EUniversity of Southern Queensland, Faculty of Engineering and Surveying, West Street, Toowoomba, \\ Qld 4350, Australia. \\ FCorresponding author. Email: allan.peake@csiro.au
}

\begin{abstract}
In-crop nitrogen $(\mathrm{N})$ application is used widely in rainfed winter wheat production to reduce lodging risk; however, uncertainty exists as to its ability to reduce lodging risk in subtropical irrigated wheat production without simultaneously reducing yield potential. The objective of this study was therefore to determine whether in-crop $\mathrm{N}$ application reduces lodging risk without reducing yield of irrigated spring wheat in a subtropical environment. Irrigated small-plot experiments were conducted to compare the effect of alternative $\mathrm{N}$ timing on lodging and yield in two cultivars. Variable $\mathrm{N}$ regimes were imposed during the vegetative growth phase, after which additional $\mathrm{N}$ was applied to ensure that total season $\mathrm{N}$ application was uniform across N-timing treatments. Treatments with low $\mathrm{N}$ at sowing had significantly less lodging and were the highest yielding, exhibiting yield increases of up to $0.8 \mathrm{tha}^{-1}$ compared to treatments with high $\mathrm{N}$ at sowing. Increased leaf area index, biomass and tiller count at the end of the vegetative growth phase were correlated with increased lodging in both cultivars, although the strength of the correlation varied with cultivar and season. We conclude that canopy-management techniques can be used to simultaneously increase yield and decrease lodging in irrigated spring wheat in the subtropics, but require different implementation from techniques used in temperate regions of Australia.
\end{abstract}

Additional keywords: $\mathrm{G} \times \mathrm{E} \times \mathrm{M}$, in-season nitrogen, irrigation, plant population, split nitrogen, yield potential.

Received 12 February 2016, accepted 30 May 2016, published online 9 September 2016

\section{Introduction}

Achieving high wheat yields in both irrigated and rainfed environments has been limited by the disorder known as lodging (Stapper and Fischer 1990b; Berry et al. 2004; Peake et al. 2014), defined as the 'permanent displacement of plant shoots from an upright position' (Pinthus 1974). Yield losses of up to $80 \%$ have been recorded in severely lodged crops, partly due to the physiological disruptions that occur in a lodged crop (e.g. reduced radiation-use efficiency caused by a less efficient canopy structure), and partly because harvesting machinery cannot completely glean the lodged crop from the soil surface (Berry et al. 2004). Lodging can also reduce grain quality (Pinthus 1974; Fischer and Stapper 1987), which further decreases economic returns.

Lodging is managed by using altered agronomic practices and the use of genetically improved, semi-dwarf wheat cultivars with greater resistance to lodging (Reitz and Salmon 1968; Pinthus 1974). Although plant genetic improvement is a long-term task, improved agronomic practices can be implemented quickly. This is pertinent to the irrigation districts of subtropical Australia, where high grain prices have recently stimulated a rapid expansion in irrigated wheat production, and yields are constrained by lodging (Peake et al. 2014).

Reduced light quantity and quality have been demonstrated to weaken stems and surface roots and increase lodging risk (Sparkes and King 2008), suggesting that agronomic practices that increase crop vigour and canopy density also increase lodging risk. This supports numerous studies in spring and winter wheat demonstrating lodging reduction through practices that reduce canopy size. These practices include reduced seeding rates (Stapper and Fischer 1990a; Easson et al. 1993; Webster and Jackson 1993), later sowing dates (Berry et al. 2000; Spink et al. 2000), and the application of plant growth regulators (Herbert 1982; Knapp et al. 1987; Crook and Ennos 1995; Tripathi et al. 2003). Such practices are known as 'canopy-management' techniques and are used in rainfed winter wheat production to improve grain yield through reduced biomass production, better access to nutrients later in the season and decreased lodging risk (Sylvester-Bradley et al. 1997; Sylvester-Bradley et al. 2000).

Decreasing nitrogen $(\mathrm{N})$ availability during the vegetative growth phase is another canopy-management technique that 
has been widely demonstrated to reduce lodging (Mulder 1954; Kheiralla et al. 1993; Crook and Ennos 1995; Berry et al. 2000; Tripathi et al. 2003). However, a feature of these and other studies was that total-season $\mathrm{N}$ availability varied between treatments. Lodging reductions in these studies may therefore have been achieved by lowering the yield potential of lowlodging treatments, and it remains unclear whether in-season $\mathrm{N}$ application can reduce lodging risk without reducing yield potential. Several studies have attempted to address this uncertainty with experiments that varied sowing $\mathrm{N}$ application before applying complementary in-season $\mathrm{N}$ rates to ensure that total-season $\mathrm{N}$ was the same for all treatments. Unfortunately, owing to lack of lodging or other experimental limitations, they were unable to demonstrate conclusively that in-crop $\mathrm{N}$ application reduces lodging while maintaining maximum yield potential.

Studies by Widdowson et al. (1961) and Bremner (1969) in rainfed winter wheat demonstrated reduced lodging with either unchanged or increased yield associated with in-crop application of $\mathrm{N}$ compared with the same amount of $\mathrm{N}$ applied at sowing. However, their yield levels $\left(4-5 \mathrm{tha}^{-1}\right)$ suggested that grain yield was limited through water or nutrient limitations, and may not be applicable to modern spring wheat germplasm capable of yielding $8 \mathrm{tha}^{-1}$. Islam et al. (2002) conducted an investigation of split $\mathrm{N}$ timings at different application rates and found a yield advantage associated with in-season $\mathrm{N}$ application at yield levels of 4-5 tha ${ }^{-1}$, but observed no lodging. Hobbs et al. (1998) presented data from an unknown location indicating that incrop $\mathrm{N}$ application reduced lodging risk of irrigated spring wheat in a subtropical environment, but no yield data were presented for that experiment. In field monitoring conducted before the present study, Peake et al. (2014) found reduced lodging and decreased lodging-related yield gaps in fields where $\mathrm{N}$ was applied in-crop; however, the use of in-crop $\mathrm{N}$ application was confounded with location and season. In the most applicable study identified, Fischer (1993) investigated split N applications in high-yielding (up to $7.5 \mathrm{tha}^{-1}$ ), irrigated spring wheat on low-fertility soils and found that delaying $\mathrm{N}$ application to growth stage 31 (Zadoks et al. 1974) did not reduce yield. However, no lodging was observed in the experiment, which was conducted in a temperate environment with a substantially longer growing season than the subtropical environments applicable to the present study.

Although previous research suggests that in-crop $\mathrm{N}$ application could be used to reduce lodging risk of irrigated wheat in the subtropics, it remains unclear whether it can effectively reduce lodging without reducing yield potential. Additionally, crop development progresses nearly twice as quickly in spring wheat grown in the subtropics than in winter wheat grown at higher latitudes. Accelerated crop development decreases the opportunity for nutrient uptake, especially in lowfertility situations (Evans 1993), and may hinder the ability of subtropical spring wheat to recover from an early $\mathrm{N}$ deficit and/or lower seeding rates and achieve maximum yield potential. Therefore, the objective of this study was to determine whether the canopy-management techniques of in-crop $\mathrm{N}$ application and decreased plant population reduce lodging risk without reducing yield of irrigated spring wheat in subtropical Australia.

\section{Methods}

\section{Experimental design}

Experiments were conducted at the Gatton CSIRO Research Station $\left(27.54^{\circ} \mathrm{S}, 152.33^{\circ} \mathrm{E}\right)$ in 2009 and 2011. Experiments aimed to compare lodging susceptibility and yield of alternative $\mathrm{N}$-timing strategies in combination with different plant populations. Nitrogen timing $\times$ plant population treatments were tested in combination with two cultivars, EGA Gregory (a long-season cultivar hereafter referred to as Gregory) and Kennedy (a quick-maturing cultivar), both of which are whitegrained semi-dwarf bread-wheats (Triticum aestivum L.). Both Gregory and Kennedy are protected by Plant Breeders Rights legislation within Australia.

All experiments were irrigated with hand-shift sprinklers, which produced droplet sizes of 4-5 $\mathrm{mm}$ diameter, considered equivalent to average rainfall droplet size. Both irrigation events and rainfall events triggered lodging (particularly when accompanied by wind), although the relative intensity of individual lodging events was not assessed because all plots were subjected to the same conditions.

The standard plot configuration for all experiments was equivalent to the commercial sowing configuration known as 'two metre beds': a section of wheat separated by irrigation furrows such that the distance between the centre of adjacent furrows is $2 \mathrm{~m}$. This standard planting configuration was achieved by sowing seven rows (with six inter-row spacings of $23.3 \mathrm{~cm}$ ) to create a $1.4-\mathrm{m}$-wide section of wheat, separated by 60-cm-wide wheel-track gaps (which are also known as 'simulated furrow-gaps'). The plots were sown on flat ground with no raised beds. An alternative plot-row configuration was also sown in the 2009 experiments, with the objective of investigating the yield potential and lodging susceptibility of simulated 1-m-wide irrigation beds. These plots contained two sets of three rows of wheat separated by a $60-\mathrm{cm}$ gap in the middle of the plot, thus representing a pair of 1-m-wide beds covering the same area as a standard 2-m-wide plot. All plots were sown to be $7 \mathrm{~m}$ in length, before plot-ends were trimmed to create 5-m-long plots on the day of harvest.

Growth stage (GS) ratings were carried out by using the decimal code reported by Tottman (1987), which discriminates in more detail between growth stages around floral initiation than the decimal code proposed by Zadoks et al. (1974) that is commonly used by Australian researchers and agronomists.

In 2009, four adjacent experiments were conducted in the same field, each of which contained a single cultivar. The experiments were sown on different dates, 13 May (cv. Gregory) and 5 June (cv. Kennedy), in an attempt to optimise yield potential for the phenology of each cultivar. Two of the experiments (one containing each cultivar) were conducted on a section of the field with low residual soil $\mathrm{N}$ that had been prepared by growing and harvesting biomass from a forage sorghum crop. These two experiments had the majority of their N requirement applied 'in-crop', at GS32 and GS39 (Tottman 1987). The other two experiments (one for each cultivar) were conducted on an adjacent section of the same field that had been fallowed, and contained the majority of the season $\mathrm{N}$ requirement as residual soil $\mathrm{N}$ present at sowing. Field history of the two areas was identical before the forage 
crop, and soil testing revealed no nutrient deficiencies (other than $\mathrm{N}$ ) in either section of the field. The aim of the $\mathrm{N}$ application strategies was to create differential $\mathrm{N}$ levels during tillering (the vegetative growth phase), after which non-limiting amounts of $\mathrm{N}$ would be applied. Nitrogen application regimes and residual soil $\mathrm{N}$ levels for the experiments are presented in Table 1.

Nitrogen regime was varied minimally within each 2009 experiment owing to concerns that highly variable application rates of $\mathrm{N}$ could influence neighbouring plots. Each experiment was a $2 \times 3$ factorial consisting of the two bed configurations (1-m or 2-m beds), and three agronomic management regimes: 100 or 200 seeds $\mathrm{m}^{-2}$ sown without additional $\mathrm{N}$, and 200 viable seeds $\mathrm{m}^{-2}$ sown with an additional $50 \mathrm{~kg} \mathrm{ha}^{-1} \mathrm{~N}$ applied at sowing. The aim of the seed rates was to establish contrasting plant populations of $\sim 100$ plants $\mathrm{m}^{-2}$ (the standard plant population used in rainfed wheat production in the northern grains region) and 200 plants $\mathrm{m}^{-2}$ (the maximum recommended plant population for irrigated wheat growing in southern Australia; Lacy and Giblin 2006). The additional sowing N was applied to the appropriate treatments as urea, spread by hand before emergence and incorporated with an irrigation of $20 \mathrm{~mm}$. Plots with fertiliser $\mathrm{N}$ applied at sowing had less $\mathrm{N}$ applied later in the season (Table 1) to ensure uniform season availability of $\mathrm{N}$ between treatments. When sowing the experiment, one bed configuration was used exclusively in each planting run, thus creating a split-plot design. Each treatment was replicated three times, except for the treatments comprising 200 viable seeds $\mathrm{m}^{-2}$ sown with an additional $50 \mathrm{~kg} \mathrm{Nha}^{-1}$. These were replicated only twice because of space limitations in the irrigated area.

Visual observations of canopy colour in 2009 indicated that low-N plots had not accessed $\mathrm{N}$ from adjacent high-N plots during the vegetative growth phase. Therefore, in 2011, all $\mathrm{N}$ treatments were included within the same experiment. A forage sorghum crop was grown and baled in the summer of 2010-11 to decrease the residual soil $\mathrm{N}$ for the entire experimental area. The 2011 experiments used only the standard 2-m-wide plots. The factorial design included two cultivars, three $\mathrm{N}$ regimes and two seeding rates (100 and 200 seeds $\mathrm{m}^{-2}$ ) across three replicates. The randomisation of cultivars was restricted to separate blocks sown within each replicate on 13 May (Gregory) and 3 June (Kennedy) to optimise yield potential for the phenology of each cultivar while allowing statistical comparison between the two cultivars. Within each sowing date 'block', the treatments were randomly applied as per a randomised block design. Rain between the two sowing dates meant that, as also occurred in 2009, the difference between sowing dates was longer than intended. The three $\mathrm{N}$ regimes (Table 1) had varying rates of N applied at sowing, GS31 and flag leaf emergence. The second application (GS31) was carried out at an earlier growth stage than in 2009, because visible $\mathrm{N}$ stress in the low-N treatments was already severe from the lower soil residual N status compared with 2009.

\section{Field measurements}

Soil samples were taken on the day of sowing to determine the water and $\mathrm{N}$ contents of the soil to a depth of $180 \mathrm{~cm}$. Sowing-soil samples were analysed for gravimetric soil-water content, nitrate- $\mathrm{N}$ concentration, soil organic carbon and $\mathrm{pH}$. Four or five cores were collected from the experimental area in each year, and split into depth layers 0-15, 15-30 and 30-60 cm and in further $30-\mathrm{cm}$ increments to $180 \mathrm{~cm}$. Depth layer samples from all cores were combined to give a single sample for each depth layer. The seven depth-layer samples from each experiment were then split into two samples, one for soil $\mathrm{N}$ and one for soil water. Samples for $\mathrm{N}$ analysis were dried at $40^{\circ} \mathrm{C}$ and the nitrate- $\mathrm{N}$ content of the samples was determined by using a $1: 5$ soil: water extraction (method 7B1, water-soluble nitrate; Rayment and Higginson 1992). The 1:5 soil: water extraction was also used to determine $\mathrm{pH}$, and organic carbon assays were obtained by using the Walkley and Black method (methods 4A1 and 8B1, respectively; Rayment and Higginson 1992). Soil-water samples used in determining gravimetric moisture content were weighed in the field and then dried at $105^{\circ} \mathrm{C}$ for a minimum of $48 \mathrm{~h}$. Dry weight was determined only once sample weights showed no weight decrease over a period of $6 \mathrm{~h}$.

Biomass samples were taken from $0.5 \mathrm{~m}^{2}$ sections of the plot comprising a $25 \mathrm{~cm}$ section across the entire 2-m plot width, which thus included a proportionate area of the simulated 'furrow gap'. Samples were collected at GS31 or 32, and at anthesis and maturity. Samples were dried at $80^{\circ} \mathrm{C}$ for a minimum of $48 \mathrm{~h}$ and were not removed until sample weights showed no further decrease over a 6 -h period. Leaf area was measured with a LI-3100 leaf area meter (LI-COR Biosciences, Lincoln, NE, USA) on a subsample of all biomass cuts taken before maturity and used to calculate leaf area index (LAI). Concentration of $\mathrm{N}$ in the aboveground biomass was measured via the Dumas combustion method with a vario MACRO cube analyser (Elementar, Hanau, Germany), and multiplied by aboveground

Table 1. Residual soil N and in-crop N regimes for the Gatton 2009 and 2011 experiments

\begin{tabular}{|c|c|c|c|c|c|c|c|}
\hline & \multicolumn{4}{|c|}{ Gatton 2009} & \multicolumn{3}{|c|}{ Gatton 2011} \\
\hline & $\begin{array}{c}\text { Low } \\
\text { sowing } \\
\mathrm{N}\end{array}$ & $\begin{array}{c}\text { Low } \\
\text { sowing } \\
\mathrm{N}+50\end{array}$ & $\begin{array}{l}\text { High } \\
\text { sowing } \\
\mathrm{N}\end{array}$ & $\begin{array}{c}\text { High } \\
\text { sowing } \\
\mathrm{N}+50\end{array}$ & $\begin{array}{c}\text { Low } \\
\text { sowing } \\
\mathrm{N}\end{array}$ & $\begin{array}{c}\text { Medium } \\
\text { sowing } \\
\mathrm{N}\end{array}$ & $\begin{array}{c}\text { High } \\
\text { sowing } \\
\mathrm{N}\end{array}$ \\
\hline & \multicolumn{4}{|c|}{$\mathrm{kg} \mathrm{ha}^{-1} \mathrm{~N}$} & \multicolumn{3}{|c|}{$\mathrm{kgha}^{-1} \mathrm{~N}$} \\
\hline Soil $\mathrm{N}$ at sowing (to $180 \mathrm{~cm}$ ) & 60 & 60 & 125 & 125 & 15 & 15 & 15 \\
\hline Fertiliser N (sowing) & & 50 & & 50 & 0 & 50 & 150 \\
\hline Fertiliser N (GS31-32) ${ }^{*}$ & 190 & 140 & 125 & 75 & 200 & 150 & 50 \\
\hline Fertiliser N (flag leaf) & 50 & 50 & 50 & 50 & 50 & 50 & 50 \\
\hline Total soil + fertiliser $\mathbf{N}$ & 300 & 300 & 300 & 300 & 265 & 265 & 265 \\
\hline
\end{tabular}

${ }^{*}$ Top-dressing occurred at GS32 in 2009, and GS31 in 2011. 
biomass to calculate $\mathrm{N}$ uptake. Data for $\mathrm{N}$ uptake were available only for the 2011 experiment, because biomass samples from 2009 were discarded after being damaged when a storeroom flooded.

Grain was harvested from the plots by using mechanised, small-plot headers. Plot yields were adjusted linearly to account for the area removed when collecting biomass samples. Grain yield is reported at $12 \%$ moisture, calculated by weighing subsamples on the day of harvest then drying samples in the same way as the biomass samples. Biomass and kernel weight data are presented on a dry-weight basis. Grain and biomass yield were calculated for the entire plot width, which included a portion of unsown wheel track situated within the harvested area.

\section{Lodging ratings and statistical analyses}

Lodging was rated where possible on the first day after each potential lodging event (rainfall or irrigation), and every 4-5 days between lodging events. Ratings for a given day were similar to those used by Mulder (1954), consisting of the average stem angle from vertical for the whole plot. This was used to calculate average lodging during grainfill (also referred to as 'grainfill lodging') by multiplying each daily score by the number of days before the next score was taken, and then averaging these over the number of days between anthesis and harvest. This method quantifies the likelihood that lodging may have caused physiological disruption to the crop. By contrast, the lodging score at harvest (e.g. Stapper and Fischer 1990b) may be wholly due to a single, late lodging event immediately before harvest, and not reflect on the development of lodging through the season.

Experiments were analysed by linear mixed models with the REML procedure in GENSTAT (version 14th Edition (VSN International, Hemel Hempstead, UK). In 2009, the four experiments were analysed together in a multi-environment analysis (with a split-plot design within each of the four experiments (considered fixed effects) due to the 1-m v. 2-m bed comparison), to determine whether agronomic treatments interacted with cultivar or residual soil $\mathrm{N}$ level in the four different experiments. The statistical analysis examined the factorial structure of the three agronomic management regimes across the two bed configurations, both of which were also designated as fixed effects. The treatment structure of residual soil $\mathrm{N}$ level $\times$ bed configuration $\times$ management regime was further explored by partitioning their effects within each cultivar.

Table 2. Average daily temperature, rainfall and irrigation volumes for the experimental periods in 2009 and 2011

\begin{tabular}{|c|c|c|c|c|c|c|c|}
\hline & May & June & July & Aug. & Sept. & Oct. & Total \\
\hline \multicolumn{8}{|c|}{ Average daily temperature $\left({ }^{\circ} \mathrm{C}\right)$} \\
\hline 2009 & 17.0 & 14.4 & 13.1 & 16.8 & 18.7 & 20.7 & \\
\hline 2011 & 16.0 & 13.6 & 12.9 & 14.8 & 16.8 & 19.5 & \\
\hline Long-term & 16.9 & 14.2 & 13.2 & 14.4 & 17.3 & 20.4 & \\
\hline \multicolumn{8}{|c|}{ Irrigation + rainfall $(\mathrm{mm})$} \\
\hline 2009 & 129 & 56 & 96 & 74 & 145 & 50 & 550 \\
\hline 2011 & 85 & 33 & 130 & 122 & 132 & 147 & 649 \\
\hline
\end{tabular}

Square-root transformation was necessary before analysis of average lodging during grainfill, and the results reported have been back-transformed. The treatment structure was also partitioned in the 2011 analyses to investigate the factorial combination of seed rate $\times \mathrm{N}$-regime $\times$ cultivar (each of which was designated as a fixed effect). In all analyses, the level of significance was set at $P=0.05$ unless stated otherwise. The least significant difference (1.s.d.) procedure was used to compare levels of an effect if the $F$-test was significant.

\section{Results}

\section{Field observations}

\section{Seasonal conditions}

In 2009, temperatures were slightly above average between sowing and anthesis, after which temperatures were close to the long-term average for the remainder of the growing season (Table 2). In 2011, temperatures were slightly below average during tillering, and were approximately equal to the long-term average for the remainder of the growing season. Each experiment had $>150 \mathrm{~mm}$ stored soil water at sowing, and inseason rainfall and irrigation combined was at least $500 \mathrm{~mm}$ for each experiment (Table 2). This ensured $>650 \mathrm{~mm}$ of water was available for growing-season evapotranspiration when taking rainfall, stored soil water and irrigation into account.

\section{Agronomic characteristics of monitored paddocks}

The low- $\mathrm{N}$ regimes induced visible $\mathrm{N}$ stress in both years. In 2009, the low-N plots were moderately yellowed at GS32 and had a distinctly different canopy structure (shorter and more upright leaves) than the high-N plots. In 2011, the low-N plots showed extreme yellowing and stunting by the end of tillering, and the decision was taken to apply in-season $\mathrm{N}$ at an earlier growth stage (GS31). Lodging was severe in 2009, with lodging in many plots beginning before anthesis following an irrigation event. Lodging was less severe in 2011, not beginning in any treatment until after anthesis. When lodging occurred, it invariably began in the centre rows of the experimental plots, followed by lodging in the edge rows in treatments where lodging was severe.

\section{Analysis of management regime $\times$ bed type across experiments in 2009}

An analysis of the management $\times$ bed type factorial design was conducted across the four 2009 experiments to determine whether the effect of the agronomic treatments was consistent across cultivars and/or soil residual N levels. Only two of 12 traits had significant interaction between the management regimes and experiments (Table 3); hence, the effect of agronomic management was generally stable across the two cultivars and both residual $\mathrm{N}$ levels for the measured traits.

Plant density varied between experiments in 2009. The two experiments with cv. Kennedy averaged $65 \%$ establishment (number of emerged seedlings per 100 viable seeds sown), whereas the cv. Gregory experiments averaged $40 \%$ establishment. Low establishment rates were caused by difficulties in achieving the ideal sowing depth, which arose from the overly wet soil conditions at sowing. Final plant 
Table 3. REML $F$-probabilities and main-effect means from the analysis of management $\times$ bed type $\times$ experiment, Gatton 2009

Biomass reported on a dry-weight basis; grain yield reported at $12 \%$ moisture. LAI, Leaf area index $\left(\mathrm{cm}^{2} \mathrm{~cm}^{-2}\right)$. Level of N at sowing: LN, low; HN, high. SR, Seed rate; $50 \mathrm{~N}, 0 \mathrm{~N}$, rate of $\mathrm{N}$ applied at seeding $\left(\mathrm{kg} \mathrm{ha}^{-1}\right){ }^{*}$, Indicates significant $(P<0.05) F$-probabilities. Within the same main-effect group, means followed by the same letter are not significantly different $(P>0.05)$; main-effect groups with no letters were not tested for significant differences because higher order interactions were present. 1.s.d., Average of least significant difference for all pairwise comparisons; n.a., not applicable because $F$-probability was not significant or higher order interactions were present

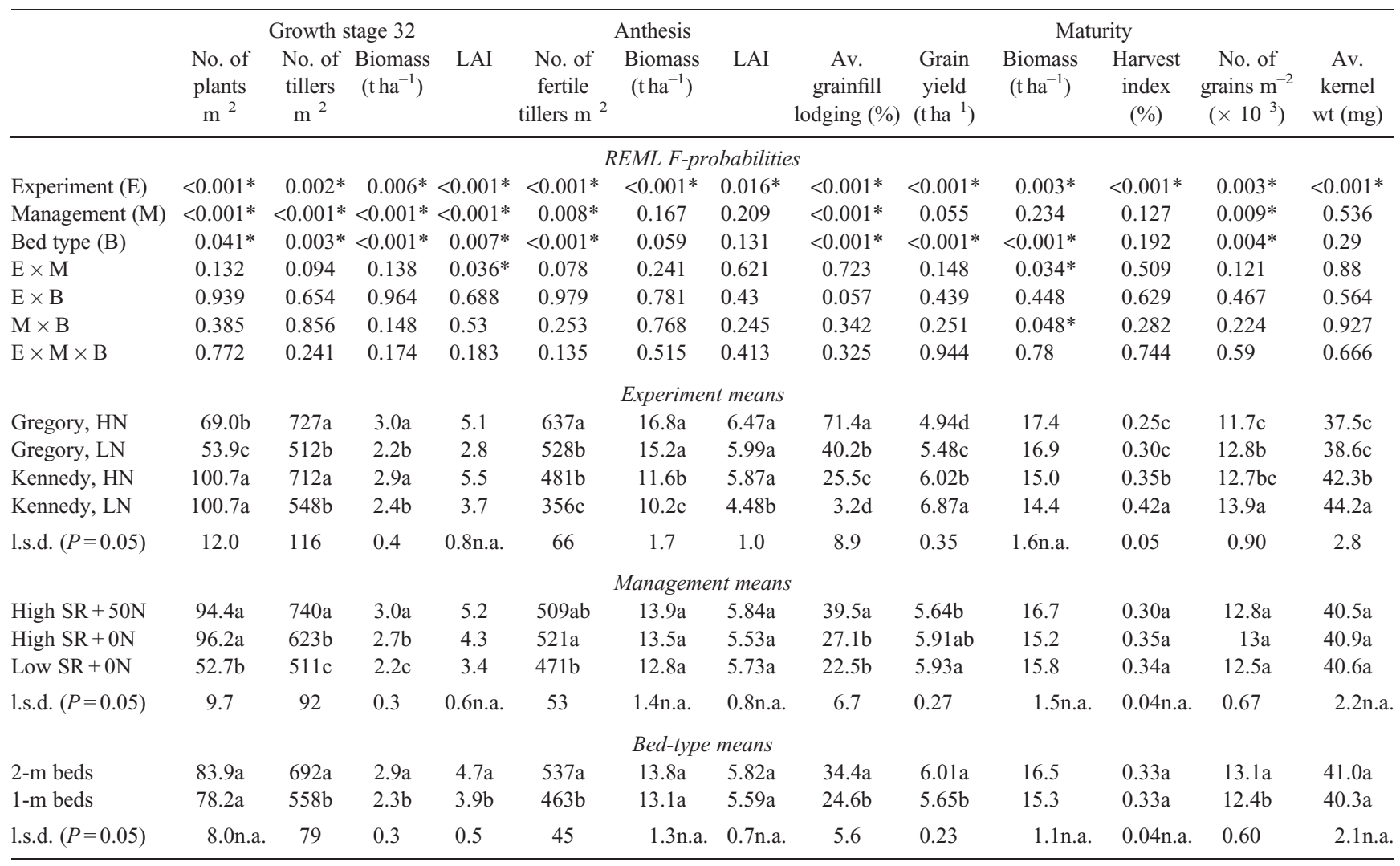
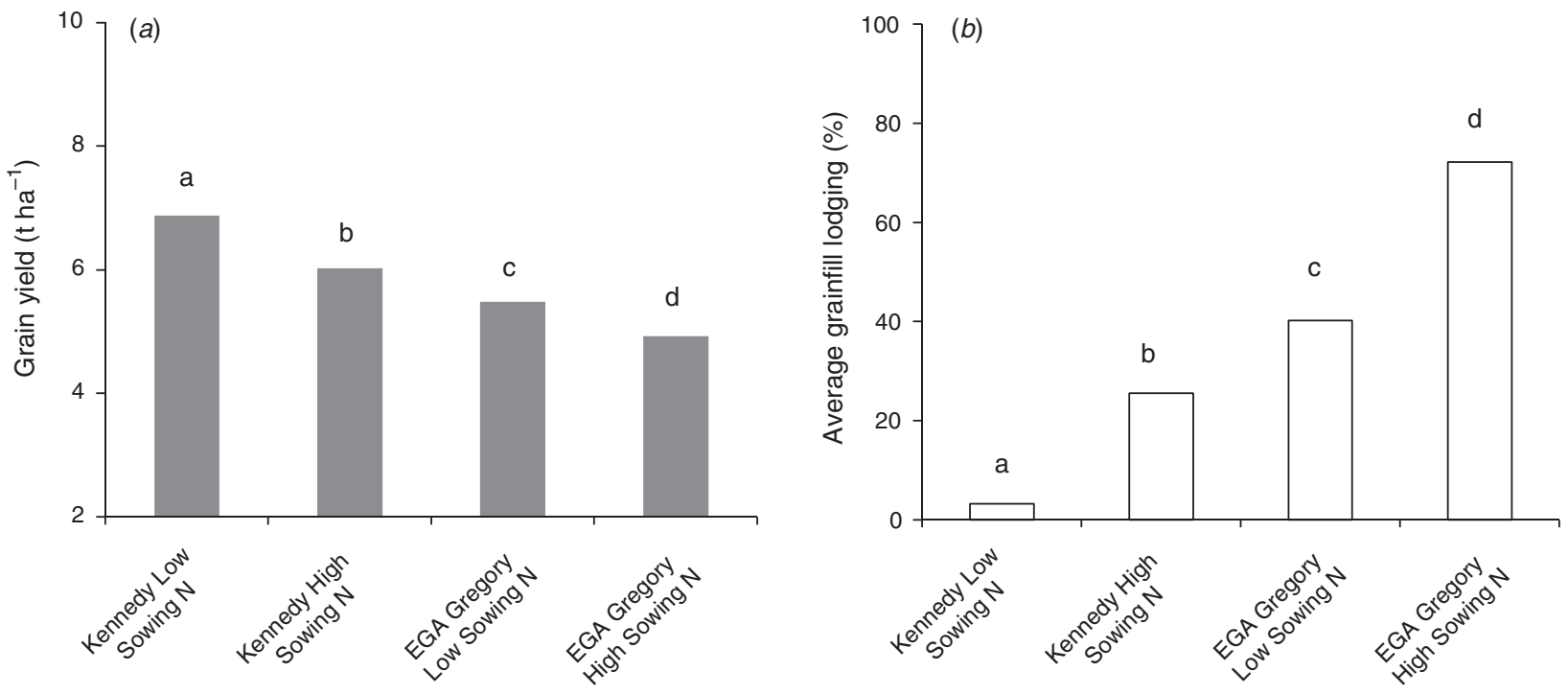

Experiment

Fig. 1. (a) Average grain yield and (b) average grainfill lodging for the four 2009 experiments. All means for grain yield and lodging are significantly different $(P<0.05)$ as indicated by different letters. 
populations were therefore lower than intended, with high and

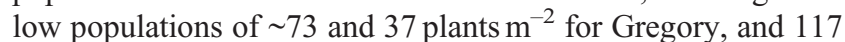
and 68 plants $\mathrm{m}^{-2}$ for Kennedy. Established plant populations were not significantly different between bed configurations or between $\mathrm{N}$ treatments (Table 3 ).

Although cultivars were sown on separate days in an attempt to synchronise anthesis, rain between sowing dates delayed the sowing of the quicker maturing cultivar (Kennedy). Anthesis date was not rated for each individual plot because of the difficulty of assessing anthesis in heavily lodged plots; however, anthesis was observed to occur $\sim 7$ days earlier in Gregory (3 September) than Kennedy (10 September).

\section{Analysis of grain yield and average grainfill lodging in 2009}

Significant differences were observed between experiments for grainfill lodging and grain yield (Table 3), with grain yield highest in the least lodged experiments (Fig. 1). The experiments with greater residual soil $\mathrm{N}$ available at sowing yielded less and lodged more than the duplicate experiments where $\mathrm{N}$ was primarily applied in-crop (Fig. 1). The grain yield increase obtained by applying $\mathrm{N}$ in-crop was $0.85 \mathrm{tha}^{-1}$ in Kennedy and $0.54 \mathrm{tha}^{-1}$ in Gregory (Table 3).

Within-experiment management regimes did not have a significant interaction with experiment (Table 3 ) for lodging or grain yield; therefore, the agronomic treatments in the factorial design had a similar effect across all four experiments relative to the background variation. Addition of $50 \mathrm{~kg} \mathrm{ha}^{-1}$ of $\mathrm{N}$ at sowing to the high seeding rate caused a significant increase in lodging across all four experiments, and a near-significant $(P=0.055)$ decrease in yield of $0.3 \mathrm{tha}^{-1}$, compared with treatments where the additional $\mathrm{N}$ was applied at GS32. The higher seed rate did not have significantly different grain yield or grainfill lodging from the low seeding rate, although grainfill lodging was numerically greater in the treatment with high seed rate.

The 2-m beds were significantly more susceptible to lodging than $1-\mathrm{m}$ beds (Table 3 ) but had significantly higher grain yield by $0.35 \mathrm{tha}^{-1}$ on average across experiments, probably due to the increased ground area sown in the wider bed configuration.

\section{Analysis of additional crop biomass and yield components at anthesis and maturity in 2009}

At anthesis, crop biomass, tiller count and LAI all exhibited trends similar to grainfill lodging, being highest in the Gregory experiment with high sowing $\mathrm{N}$, and lowest in the Kennedy experiment with low sowing $\mathrm{N}$, although the main effects of these traits were not always significant in the analyses (Table 3). Across management regimes, maximum values of these traits tended to occur in the treatment with high seeding rate + $50 \mathrm{~kg} \mathrm{Nha}^{-1}$, and lowest values were recorded in the treatment with low seeding rate. Unsurprisingly, these traits were also greater with the 2-m bed configuration than in the $1-\mathrm{m}$ beds when measured at anthesis.

Significant experiment $\times$ management and management $\times$ bed-type interactions were observed for maturity biomass (Table 3). This was evidenced through the experiments with Gregory (high and low sowing N) and Kennedy (low sowing N) generally exhibiting a slight increase in biomass across management regimes (Fig. 2) when listed in increasing order of lodging susceptibility. However, the Kennedy experiment with high sowing $\mathrm{N}$ deviated from this trend, probably because higher grain yield contributed to greater harvest biomass in the treatment with low sowing $\mathrm{N}$ and low seed rate.

Harvest index was significantly different between experiments, with the highest harvest index of 0.42 recorded in the least lodged (Kennedy, low sowing N) experiment (Table 3). Maximum harvest index of individual treatments within this experiment was 0.46 (data not shown), although harvest index was not significantly different between management regimes or bed types. Grain yield differences between experiments were explained by increases in both grain number and average kernel weight, but no significant differences were observed for either yield component among management regimes (Table 3 ). The increased yield of 2-m

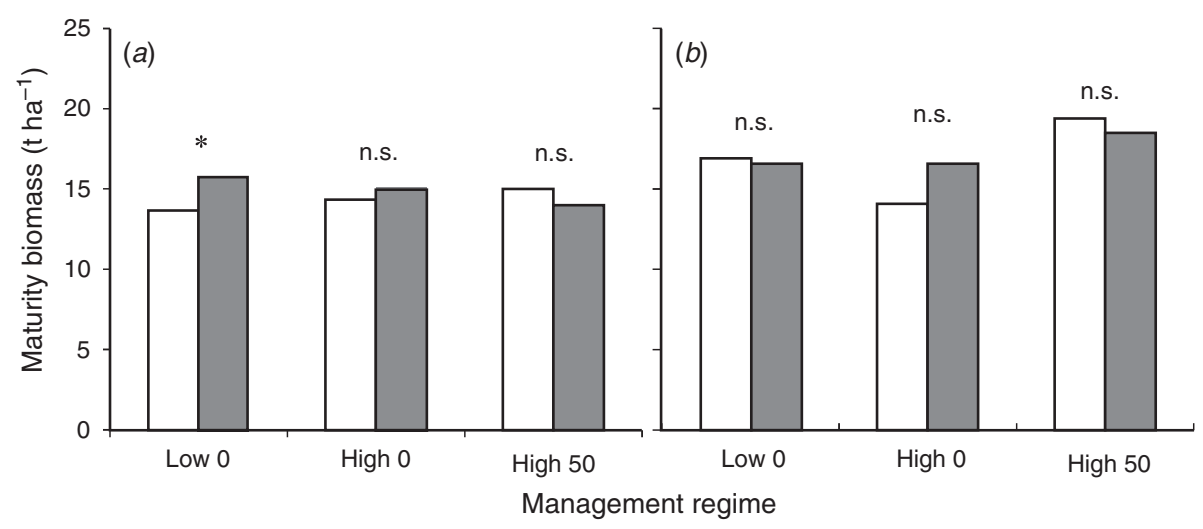

Fig. 2. Patterns of management regime $\times$ experiment interaction for maturity biomass in $(a)$ cv. Kennedy and $(b) \mathrm{cv}$. Gregory, for the experiments with low (open bars) and high (filled bars) sowing N. Low 0, Low seeding rate with nil additional sowing N; High 0 , high seeding rate with nil additional sowing N; High 50, high seeding rate with additional $50 \mathrm{~kg} \mathrm{Nha}^{-1}$ applied at sowing. For comparison of paired data: $* P<0.05$; n.s., not significantly different. 


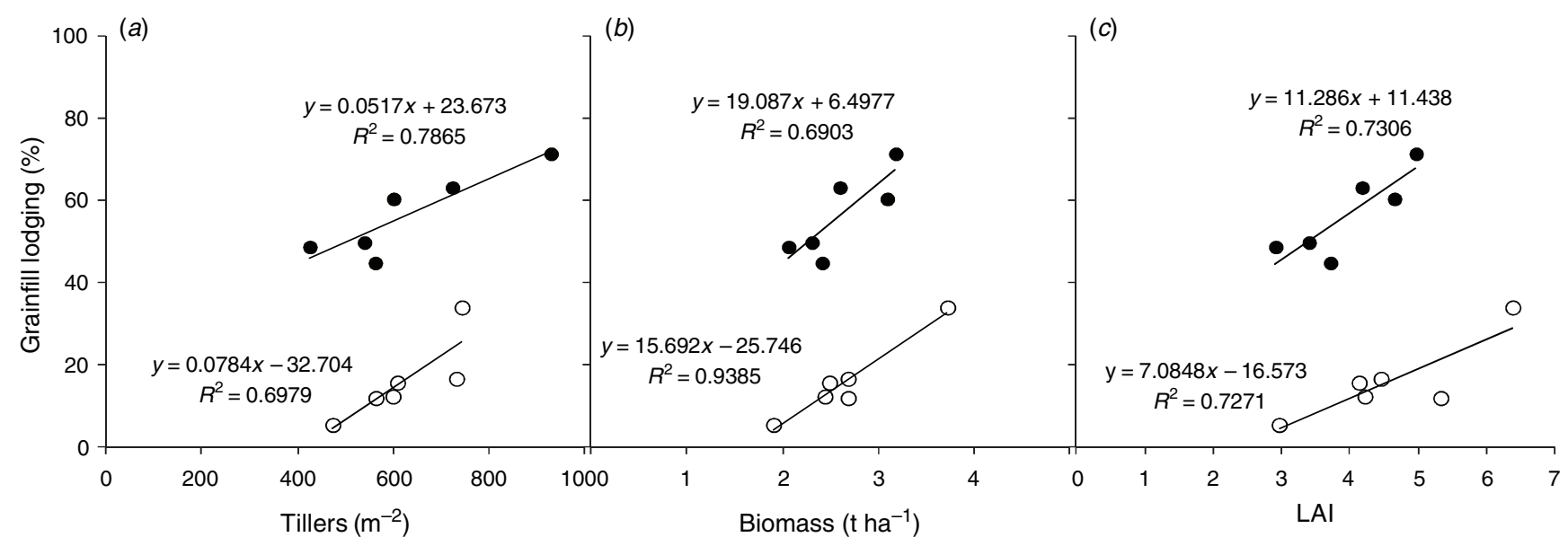

Fig. 3. Average grainfill lodging across the four experiments for each management $\times$ bed-type treatment $v$. $(a)$ tiller count, $(b)$ biomass, and $(c)$ leaf area index (LAI) measured at GS32, for the cv. Kennedy $(\bigcirc)$ and cv. Gregory $(\bullet)$ experiments.
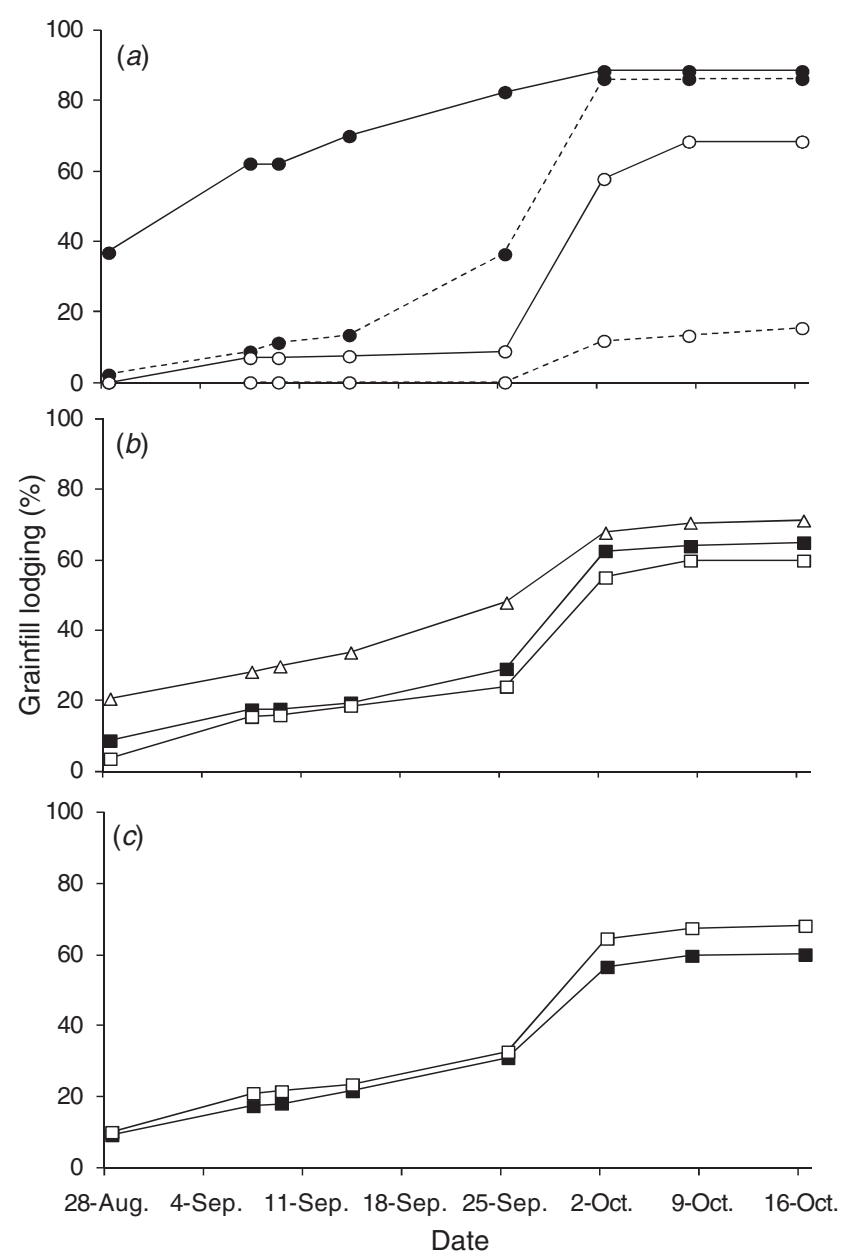

Fig. 4. Progression of grainfill lodging at Gatton in 2009 over time for the main effects. (a) Experiments: low residual soil N (- - -), high residual soil N $(-)$; cv. Kennedy $(\bigcirc)$ and cv. Gregory $(\bullet)$. (b) Management regimes: high seed rate, no additional sowing $\mathrm{N}(\mathbf{\square})$; low seed rate, no additional sowing $\mathrm{N}(\square)$; high seed rate with additional $50 \mathrm{~kg} \mathrm{Nha}^{-1}$ at sowing $(\triangle)$. (c) Bed types: 2-m beds ( $\square$ ), 1-m beds ( beds over 1-m beds was logically explained by a significant increase in grain number and non-significant increase in average kernel weight.

\section{Analysis of vegetative growth traits and their relationship to lodging in 2009}

Management and bed type had a significant effect on vegetative growth in 2009. On average across the four experiments, increased seed rate and the addition of $50 \mathrm{~kg} \mathrm{Nha}^{-1}$ at sowing significantly increased biomass production, tiller count and LAI at GS32 (Table 3). Unsurprisingly, the same traits were also significantly greater in the 2-m beds than the $1-\mathrm{m}$ beds. Significant interaction was observed between experiment and management regimes for LAI due to slightly different rates of LAI increase across management regimes between the two cultivars (data not shown).

On average across all four experiments, there was a strong linear relationship between grainfill lodging and average tiller count, biomass and LAI for each of the management $\times$ bed-type combinations (data not shown). Similar levels of correlation were observed for the same comparisons when examined separately between the Gregory and Kennedy experiments (Fig. 3); however, the $y$-axis intercept was significantly different for each cultivar, suggesting that Gregory was more susceptible to lodging than Kennedy when grown under the same agronomic management regime. Progression of lodging over time in 2009 reflected the average grainfill lodging score for all of the main-effect comparisons (Fig. 4), with no reranking observed among the main-effect comparisons between observation dates.

\section{Analysis of cultivar $\times N$ regime $\times$ seed rate in 2011}

Analysis of the cultivar $\times \mathrm{N}$ regime $\times$ seed rate factorial design was conducted for the 2011 experiment to determine whether the effects of $\mathrm{N}$ regime and seed rate were consistent across cultivars. Significant cultivar $\times$ N regime and cultivar $\times$ seed rate interactions were observed for most agronomic traits measured at GS31 (Table 4), but these interactions were rarely significant when measured at anthesis and maturity (Table 5). The effect of 
Table 4. REML F-Probabilities and main-effect and significant higher order interaction means from the analysis of cultivar $\times$ nitrogen $(N)$ regime $\times$ seed rate at GS30 at Gatton in 2011

Cv., Cultivar; SR, seed rate; LAI, leaf area index $\left(\mathrm{cm}^{2} \mathrm{~cm}^{-2}\right)$. *, Indicates significant $(P<0.05) F$-probabilities; $\dagger$, approaching significance $(P=0.055)$ and assumed significant for generating interaction means. Within the same group, means followed by the same letter are not significantly different $(P>0.05)$; main-effect groups with no letters were not tested for significant differences because higher order interactions were present. 1.s.d., Average of least significant difference for all pairwise comparisons; n.a., not applicable because $F$-probability was not significant or higher order interactions were present

\begin{tabular}{|c|c|c|c|c|c|}
\hline & $\begin{array}{l}\text { No. of plants } \\
\mathrm{m}^{-2}\end{array}$ & $\begin{array}{c}\text { No of tillers } \\
\mathrm{m}^{-2}\end{array}$ & $\begin{array}{l}\text { Biomass } \\
\left(\mathrm{t} \mathrm{ha}^{-1}\right)\end{array}$ & LAI & $\begin{array}{c}\text { N uptake } \\
\left(\mathrm{kg} \mathrm{Nha}^{-1}\right)\end{array}$ \\
\hline \multicolumn{6}{|c|}{ REML F-Probabilities } \\
\hline Cv. & $<0.001 *$ & $<0.001^{*}$ & $<0.001^{*}$ & $<0.001 *$ & 0.561 \\
\hline $\mathrm{N}$ regime & 0.892 & $<0.001 *$ & $<0.001^{*}$ & $<0.001 *$ & $<0.001 *$ \\
\hline SR & $<0.001 *$ & $0.095^{*}$ & $0.029 *$ & 0.057 & 0.905 \\
\hline $\mathrm{Cv} . \times \mathrm{N}$ regime & $0.024 *$ & 0.891 & $<0.001^{*}$ & $0.018^{*}$ & $<0.001 *$ \\
\hline $\mathrm{Cv} \times \mathrm{SR}$ & $<0.001 *$ & $0.008^{*}$ & $0.02 *$ & $0.055 \dagger$ & 0.361 \\
\hline $\mathrm{N}$ regime. $\times \mathrm{SR}$ & 0.44 & 0.937 & 0.078 & 0.133 & 0.971 \\
\hline Cv. $\times$ N regime. $\times$ SR & 0.759 & 0.512 & 0.332 & 0.829 & 0.887 \\
\hline \multicolumn{6}{|c|}{ Cultivar means } \\
\hline Gregory & 131.4 & 590 & 1.7 & 2.95 & 52.5 \\
\hline Kennedy & 95.0 & 350 & 1.4 & 1.83 & 54.6 \\
\hline 1.s.d. $(P=0.05)$ & 8.8n.a. & 73n.a. & 0.16n.a. & 0.37 n.a. & 7.3n.a. \\
\hline \multicolumn{6}{|c|}{ Sowing nitrogen regime means } \\
\hline High sowing $\mathrm{N}$ & 114.0 & $605 a$ & 2.3 & 3.89 & 91.1 \\
\hline Medium sowing $\mathrm{N}$ & 113.0 & $451 \mathrm{~b}$ & 1.5 & 2.38 & 46.6 \\
\hline Low sowing $\mathrm{N}$ & 112.6 & $349 \mathrm{c}$ & 0.8 & 1.19 & 22.9 \\
\hline 1.s.d. $(P=0.05)$ & 10.7n.a. & 89 & 0.19n.a. & 0.46n.a. & 9.0n.a. \\
\hline \multicolumn{6}{|c|}{ Seed rate means } \\
\hline High SR & 144.8 & 494 & 1.6 & 2.54 & $53.3 \mathrm{a}$ \\
\hline Low SR & 81.6 & 432 & 1.4 & 2.18 & $53.7 \mathrm{a}$ \\
\hline 1.s.d. $(P=0.05)$ & 8.8n.a. & 73n.a. & 0.16 n.a. & 0.37 n.a. & 7.3n.a. \\
\hline \multicolumn{6}{|c|}{ Cultivar $\times$ nitrogen regime means } \\
\hline Gregory, high sowing N & $124.6 \mathrm{a}$ & 741 & $2.75 \mathrm{a}$ & $5.05 \mathrm{a}$ & $101.7 \mathrm{a}$ \\
\hline Gregory, medium sowing $\mathrm{N}$ & $131.5 \mathrm{a}$ & 591 & $1.61 \mathrm{c}$ & $3.09 \mathrm{~b}$ & $40.1 \mathrm{~d}$ \\
\hline Gregory, low sowing $\mathrm{N}$ & $138.1 \mathrm{a}$ & 457 & $0.74 \mathrm{e}$ & $1.31 \mathrm{~cd}$ & $15.7 \mathrm{f}$ \\
\hline Kennedy, high sowing N & $103.4 \mathrm{~b}$ & 482 & $1.91 \mathrm{~b}$ & $2.89 \mathrm{~b}$ & $80.6 \mathrm{~b}$ \\
\hline Kennedy, medium sowing $\mathrm{N}$ & $94.4 \mathrm{bc}$ & 329 & $1.33 \mathrm{~d}$ & $1.76 \mathrm{c}$ & $53.0 \mathrm{c}$ \\
\hline Kennedy, low sowing $\mathrm{N}$ & $87.1 \mathrm{c}$ & 256 & $0.84 \mathrm{e}$ & $1.07 \mathrm{~d}$ & $30.1 \mathrm{e}$ \\
\hline 1.s.d. $(P=0.05)$ & 15.2 & 126n.a. & 0.28 & 0.64 & 12.7 \\
\hline \multicolumn{6}{|c|}{ Cultivar $\times$ seed rate means } \\
\hline Gregory high SR & $170.1 \mathrm{a}$ & $687 \mathrm{a}$ & $1.89 \mathrm{a}$ & $3.37 \mathrm{a}$ & 53.9 \\
\hline Gregory low SR & $92.7 \mathrm{c}$ & $501 \mathrm{~b}$ & $1.51 \mathrm{~b}$ & $2.56 \mathrm{~b}$ & 51.1 \\
\hline Kennedy high SR & $119.4 b$ & $332 \mathrm{c}$ & $1.35 b$ & $1.83 \mathrm{c}$ & 52.7 \\
\hline Kennedy low SR & $70.5 \mathrm{~d}$ & $368 \mathrm{c}$ & $1.37 \mathrm{~b}$ & $1.83 \mathrm{c}$ & 56.4 \\
\hline 1.s.d. $(P=0.05)$ & 12.5 & 102 & 0.22 & 0.52 & 10.4n.a. \\
\hline
\end{tabular}

$\mathrm{N}$ regime and seed rate therefore varied between cultivars at the end of the vegetative growth phase, but was more stable when measured at or after anthesis.

Establishment in 2011 was significantly greater in cv. Gregory $(87 \%)$ than in cv. Kennedy $(63 \%)$ on average across all treatments. Significant two-way interactions were observed for plant population between cultivar and both seed rate and $\mathrm{N}$ regime (Table 4), with Kennedy having higher establishment when sowing $\mathrm{N}$ levels were increased whereas no such trend was observed in Gregory, suggesting that the germination of Kennedy may have been slightly affected by low soil-N status.
Cultivar $\times$ seed rate interaction may have been caused by the increased difficulty in counting emerged plants in the Gregory plots with high seed rate, where tillering had already begun and it was not always possible to distinguish between tillers and separate plants.

Anthesis was observed 11 days earlier in Gregory (29 August) than Kennedy (9 September), with Kennedy sown later than intended because of a rain event (Table 5). Anthesis date was not significantly different between seed rates. A significant cultivar $\times \mathrm{N}$ regime interaction for anthesis date was observed whereby Gregory with low sowing $\mathrm{N}$ had delayed anthesis 
Table 5. REML $F$ Probabilities and main effect means from the analysis of cultivar $\times \mathbf{N}$ regime $\times$ seed rate at Gatton in 2011 Cv., Cultivar; SR, seed rate; LAI, leaf area index $\left(\mathrm{cm}^{2} \mathrm{~cm}^{-2}\right)$. * Indicates significant $(P<0.05) F$-probabilities. Within the same main effect group, means with the same letters are not significantly different $(P>0.05)$; main-effect groups with no letters were not tested for significant differences because higher order interactions were present. 1.s.d., Average of least significant difference for all pairwise comparisons; n.a., not applicable because $F$-probability was not significant or higher order interactions were present

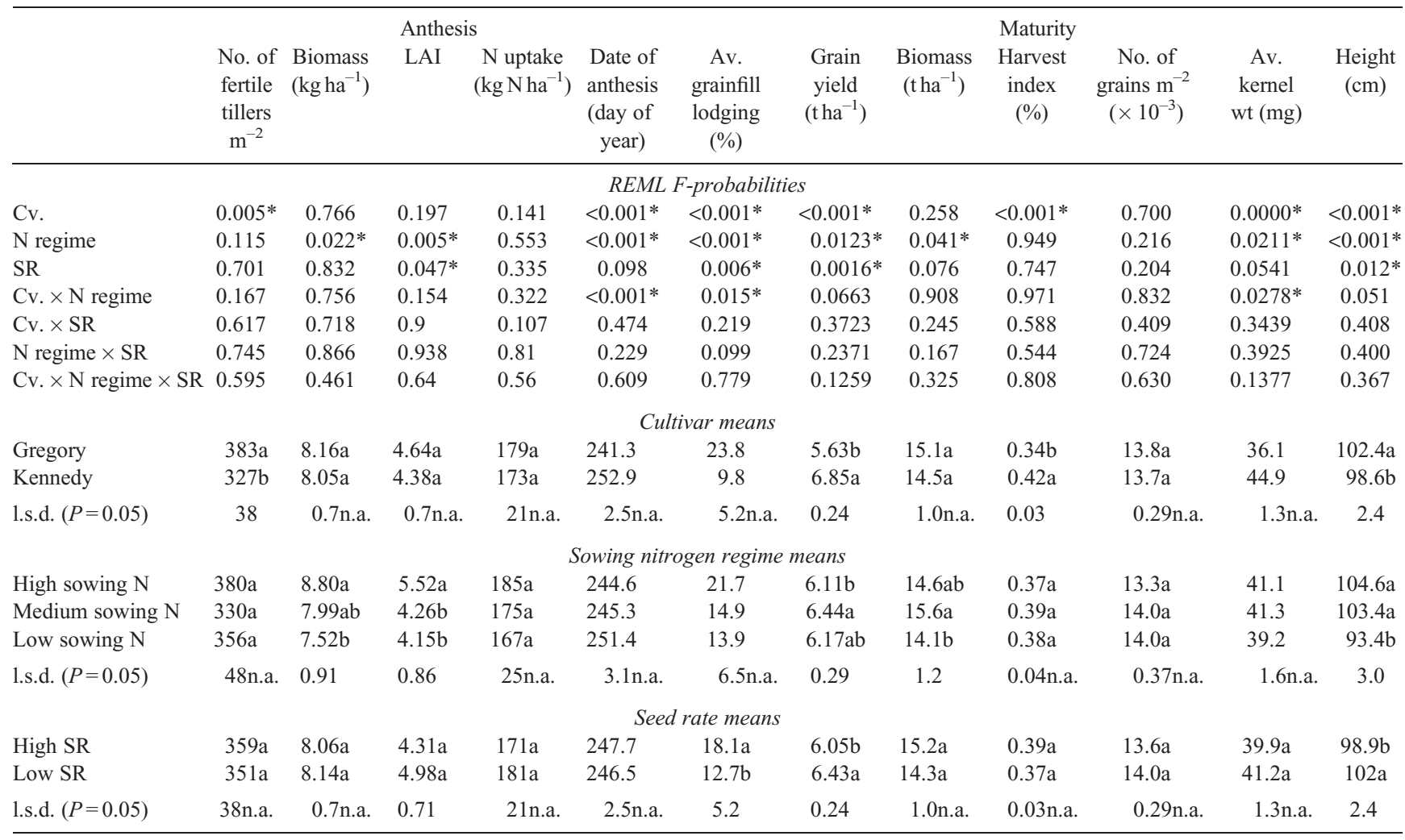

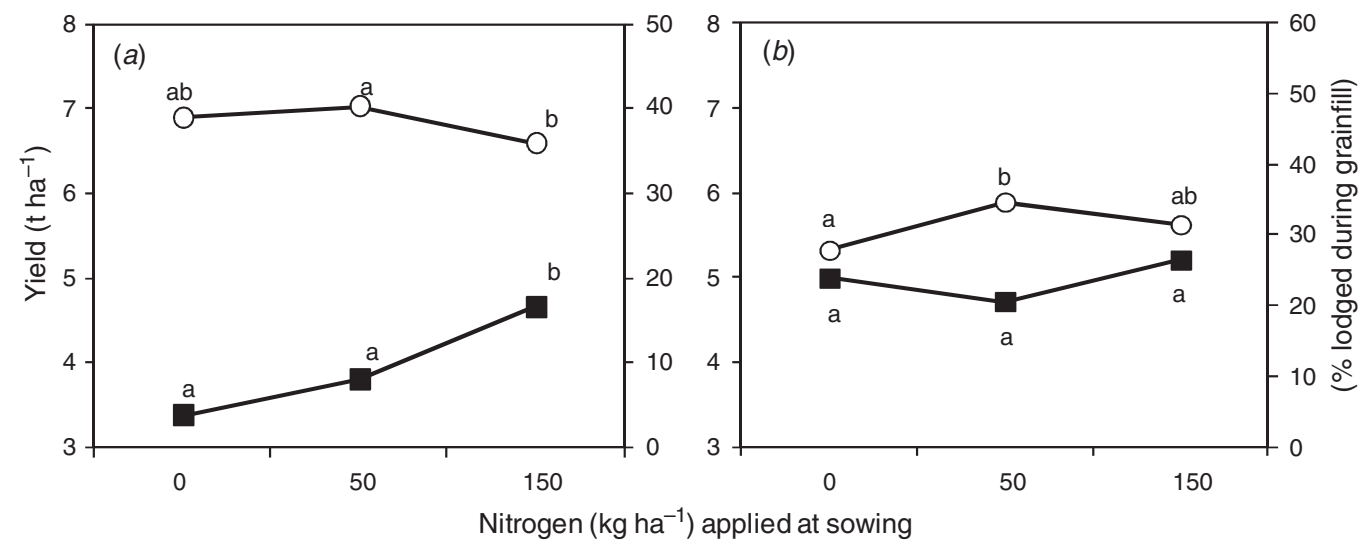

Fig. 5. Yield $(\bigcirc)$ and average lodging during grainfill

) for the three N regimes for $(a) \mathrm{cv}$. Kennedy and $(b) \mathrm{cv}$. Gregory in 2011. Means on the same response curve with the same letter are not significantly different at $P=0.05$.

relative to Gregory with high sowing N. This was caused by late tiller development after in-crop $\mathrm{N}$ application, a trend not observed to the same extent in Kennedy. Anthesis date was not strongly correlated with grain yield among $\mathrm{N}$ regime $\times$ seed rate means within varieties (data not shown), and no weather events (frost, high temperature) were observed that may have explained the lower yield of the earlier flowering Gregory plots.

\section{Analysis of grain yield and average grainfill lodging} in 2011

The only significant higher order interaction for either grain yield or grainfill lodging in 2011 was a cultivar $\times N$ regime interaction, which was significant for grainfill lodging and approaching significance $(P=0.066)$ for grain yield (Table 5). The treatments with low and medium sowing $\mathrm{N}$ in 
Kennedy were not significantly different for either yield or grainfill lodging, but did have significantly less lodging and increased grain yield compared with the high $\mathrm{N}$ treatment (Fig. 5a). The treatments with low and medium sowing $\mathrm{N}$ yielded 6.95 and $7.01 \mathrm{tha}^{-1}$, compared with $6.58 \mathrm{tha}^{-1}$ for high sowing N. In the Gregory treatments, no significant differences were observed among $\mathrm{N}$ regimes for grainfill lodging (Fig. $5 b$ ). However, grain yield was significantly lower in the treatment with low sowing $\mathrm{N}\left(5.4 \mathrm{tha}^{-1}\right)$ than medium $\mathrm{N}\left(5.87 \mathrm{tha}^{-1}\right)$, which in turn was numerically greater than but not significantly different from high sowing $\mathrm{N}\left(5.63 \mathrm{tha}^{-1}\right)$.

The main effect of seed rate was significant for both yield and grainfill lodging in 2011, with grainfill lodging of $18.1 \%$ and $12.7 \%$ for the high and low seed rates on average across cultivars and $\mathrm{N}$ rates (Table 5). The lower seed rate also produced significantly higher yields than the higher seed rate (6.4 v. $6.0 \mathrm{tha}^{-1}$ ) on average across all $\mathrm{N}$ regimes and both cultivars.

\section{Analysis of biomass and yield components at anthesis and maturity in 2011}

At anthesis, crop biomass, tiller count and LAI had numerical trends similar to grainfill lodging, but the main effects of these traits were not regularly significant in the analysis (Table 5). Anthesis tiller count was significantly greater in Gregory than in Kennedy, but was not significantly different between $\mathrm{N}$ regimes and seed rates. Anthesis biomass and LAI was significantly greater under the highest sowing $\mathrm{N}$ regime, but not significantly different between cultivars or seed rates. At maturity, biomass was not significantly different between cultivars or seed rates, but was significantly greater under medium sowing $\mathrm{N}$ than low sowing $\mathrm{N}$ (Table 5). Harvest index was significantly greater in Kennedy than in Gregory, but was not significantly different between N regimes or seed rates. No higher order interactions were observed for anthesis and maturity biomass, or harvest index. Anthesis $\mathrm{N}$ uptake was not significantly different between cultivars, $\mathrm{N}$ regimes or seed rates.
The main effect of plant height was significant for cultivar, $\mathrm{N}$ regime and seed rate (Table 5), with no significant higher order interaction observed. Gregory was significantly taller than Kennedy, and the low- $\mathrm{N}$ treatment was significantly shorter than the medium- and high-N treatments. Surprisingly, the treatments with low seed rate showed a small but significant height increase of $3 \mathrm{~cm}$ compared with the high seed rate, possibly because increased competition for $\mathrm{N}$ (and hence increased $\mathrm{N}$ stress) may have occurred in the higher plant population, decreasing height.

No significant differences were observed between treatments for grain number in 2011; however, average kernel weight varied substantially between treatments, with a significant cultivar $\times \mathrm{N}$ regime interaction observed (Table 5). There was also a near-significant main effect of seed rate $(P=0.054)$, with the low seed rate having heavier grains by $0.13 \mathrm{mg}$ on average across cultivars and $\mathrm{N}$ regimes. The significant cultivar $\times \mathrm{N}$ regime interaction was observed as a substantial decline in average kernel weight in the Gregory treatment with low $\mathrm{N}$ $(3.36 \mathrm{mg})$ compared with medium and high $\mathrm{N}$ (3.8 and $3.7 \mathrm{mg}$ ). In Kennedy, there was no difference in average kernel weight between $\mathrm{N}$ regimes, with all three between 4.48 and $4.52 \mathrm{mg}$.

\section{Analysis of vegetative growth traits and their relationship} to lodging in 2011

Cultivar, seed rate and sowing $\mathrm{N}$ regime generally had a significant effect on biomass, tiller count and LAI at the end of the vegetative growth phase (Table 4). Increased application of $\mathrm{N}$ at sowing was associated with increased biomass and tiller production and a subsequent increase in LAI in both cultivars, although the presence of significant cultivar $\times \mathrm{N}$ regime interaction meant that the proportional response to increased $\mathrm{N}$ varied between varieties for biomass and LAI (Table 4). As expected, $\mathrm{N}$ uptake in aboveground biomass was significantly lower in the low-N treatments, although a significant cultivar $\times \mathrm{N}$ regime interaction was observed. Gregory had significantly

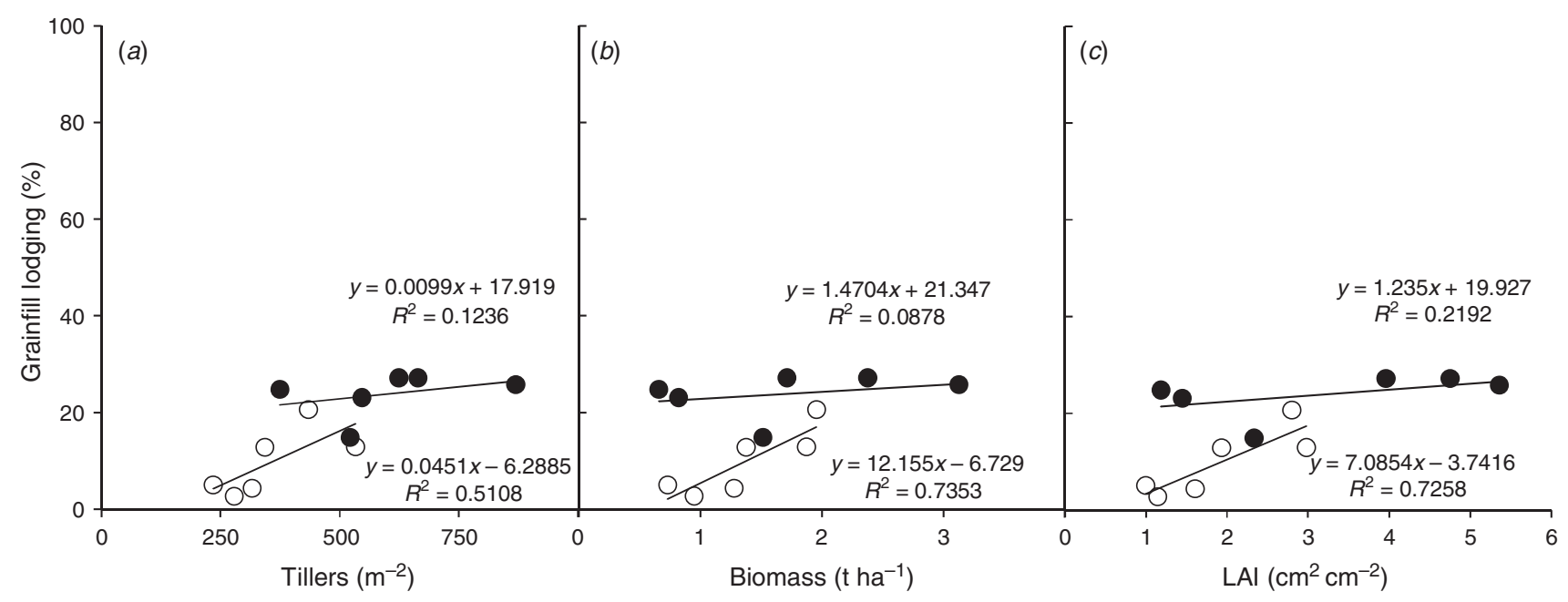

Fig. 6. Grainfill lodging $v$. (a) tiller count, $(b)$ biomass, and $(c)$ leaf area index (LAI) measured at GS30 for the six N-regime $\times$ seed-rate treatments at Gatton in 2011 for cv. Kennedy (O) and cv. Gregory $(\bullet)$. 


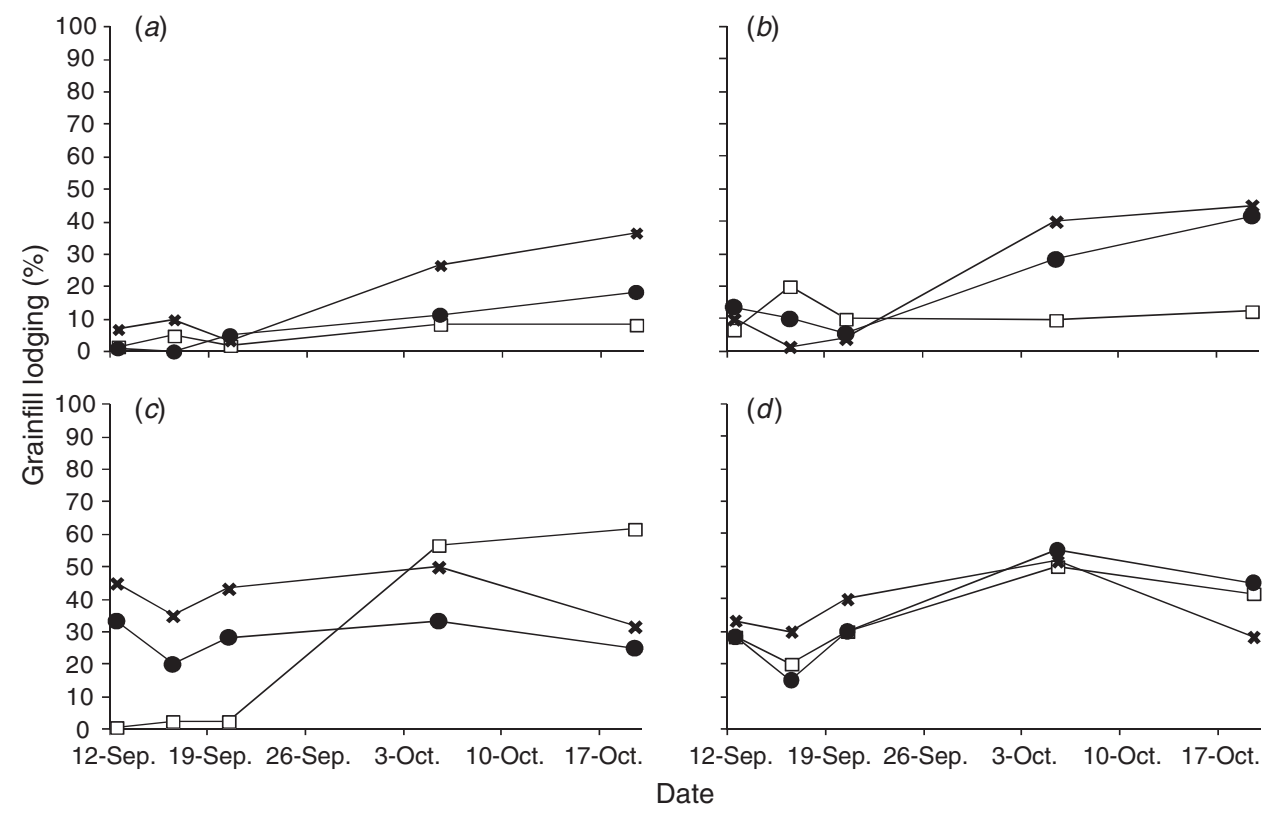

Fig. 7. Progression of grainfill lodging at Gatton in 2011 for the treatments with $(a, c)$ low and $(b, d)$ high seed rate of $(a, b)$ cv. Kennedy and $(c, d)$ cv. Gregory. Sowing N treatments: low $(\square)$, medium $(\bullet)$, high $(\mathbf{X})$.

higher $\mathrm{N}$ uptake than did Kennedy with high sowing N, but lower $\mathrm{N}$ uptake with medium and low sowing $\mathrm{N}$ (Table 4).

There was also significant seed rate $\times$ cultivar interaction for tiller count and biomass, and a near-significant interaction for LAI (Table 4). The interaction effect was observed through Gregory having significantly higher tiller count, biomass and LAI at the higher seed rate, whereas Kennedy did not have a significant response to increased seed rate for any of these traits. This suggested that Kennedy seedlings had greater ability to adjust tillering in response to variable establishment, whereas Gregory seedlings tended to tiller prolifically even when establishment was higher.

The development of early biomass and related traits in 2011 was strongly correlated with increased lodging in Kennedy, but not Gregory (Fig. 6). The absence of a strong relationship in Gregory may have been due to late lodging that occurred in the Gregory treatment with low sowing $\mathrm{N}$ and low seed rate (Fig. 7), which increased its grainfill-lodging score despite showing less lodging than the medium- and high-N treatments during early grainfill.

\section{Discussion}

The objective of this study was to determine whether the canopymanagement techniques of in-crop $\mathrm{N}$ application and reduced plant population were able to reduce lodging without decreasing yield in a subtropical environment. The results showed that treatments with the highest level of sowing $\mathrm{N}$ were typically more susceptible to lodging and lower yielding than treatments where $\mathrm{N}$ was applied in-crop, although these trends were less evident in cv. Gregory in the 2011 experiment.

The results from 2011 also showed that the high plant populations (120-170 plants $\mathrm{m}^{-2}$, depending on cultivar) were significantly more susceptible to lodging and lower yielding than the low plant populations (70-90 plants $\mathrm{m}^{-2}$, depending on cultivar), which are more like those used in rainfed cropping in subtropical Australia. However, the two plant population treatments were not significantly different for lodging or grain yield in the 2009 experiment (although lodging was numerically greater with the high plant population). This result was potentially related to the poor establishment in 2009, which resulted in plant populations much lower than intended, which in turn may have negatively influenced yield of the treatments with low plant population. The additional irrigation-bed comparisons made in 2009 also showed that crops grown on 2-m-wide beds were higher yielding but more susceptible to lodging than crops grown on 1-m-wide beds.

The trends in yield were associated with changes in both grain number and kernel weight in 2009, when lodging occurred at, or slightly before, anthesis in many treatments. In 2011, when lodging occurred in mid-grainfill for most treatments, the changes in yield were almost exclusively related to changes in kernel weight. These results are unsurprising, given that grain number in wheat is determined in the weeks before anthesis (when the 2009 treatments were beginning to lodge), and kernel weight is influenced by conditions experienced during grainfill, when lodging began in 2011.

These results agree with the experience in high-yielding, winter-wheat production where canopy-management practices are used routinely to maximise yield and decrease lodging risk (Sylvester-Bradley et al. 1997, 2000; Berry et al. 2000). They also confirm observations from a previous field monitoring study (Peake et al. 2014) on the potential benefits of canopy management for irrigated wheat production in north-eastern Australia. The results also showed that, within the range of experimental treatments, the highest yielding treatments had the lowest LAI at anthesis, with the highest yields in both years coming from treatments with anthesis LAI of 4.0-4.5. This concurs with canopy-management experiments 
in rainfed winter wheat that found achieving maximum yield did not require maximum canopy development (Sylvester-Bradley et al. 1997).

Agronomic strategies such as high seeding rates, decreased row spacing, and increased soil residual $\mathrm{N}$ at sowing have previously shown increased lodging susceptibility (Stapper and Fischer 1990b; Easson et al. 1993; Berry et al. 2004). These strategies logically increase biomass production during vegetative growth; however, none of those studies measured vegetative growth or development at the end of the vegetative growth phase. Sparkes and King (2008) subsequently used pot trials to demonstrate that artificial shading could be used to alter light quantity (photosynthetically active radiation, or PAR) and quality (the ratio of red to far-red wavelengths) and influence lodging risk by modifying the structural characteristics of wheat plants that affect lodging susceptibility (e.g. stem strength and root-plate spread). Sparkes et al. (2008) then demonstrated that PAR intercepted at GS30, on a per-plant basis, was highly correlated with root-plate spread measured just before maturity. Therefore, our results support and extend the findings of those previous studies, because increased tiller density, biomass and LAI at GS31-32 were correlated with increased lodging. These findings suggest that it may be possible to develop calibrations for crop sensors to detect lodging risk on the basis of biomass development, for a specific growth stage.

The decreased lodging susceptibility of $1-\mathrm{m}$ beds compared with 2-m beds in 2009 was also probably an effect of decreased shading, manifested in the larger number of edge rows present in the narrow-bed system. However, grain yield was still lower in the $1-\mathrm{m}$ beds, probably due to the increased ground area sown in 2-m bed systems. This was similar to the result observed by Tripathi et al. (2005) of less lodging and decreased yield in bedsown wheat compared with wheat sown on flat ground without furrow gaps.

Vegetative growth traits were related to increased grainfill lodging in both cultivars in 2009; however, the correlation in 2011 was weaker in Kennedy and almost non-existent in Gregory, which may be explained by several factors. First, several Gregory treatments lodged shortly after anthesis but recovered somewhat through phototropic stem straightening. This had the effect of mitigating average grainfill lodging in some of the earliest lodged treatments, which mirrors the results of Easson et al. (1993), who found that recovery from lodging was more likely in earlier lodged treatments. Second, the Gregory treatment with low $\mathrm{N}$ and low seeding rate showed almost no lodging for much of the grain-filling period, but then lodged heavily over the final 3 weeks. This increased its average grainfill lodging to levels comparable to other treatments that lodged mildly early in the grain-filling period without worsening in severity. Therefore, the recovery of lodging-susceptible treatments, combined with severe late lodging of treatments that showed little lodging early in grainfill, may have contributed to the weakness of the relationship between grainfill lodging and vegetative growth traits for Gregory in 2011.

The weaker relationships between lodging and vegetative traits in 2011 could also be due to effects of environmental variation on the development of lodging risk. As discussed by Baker et al. (1998) and Berry et al. (2003), other critical crop structures relating to lodging risk include (among others) stem height and centre of gravity, stem natural frequency, stem-wall thickness, ear surface area and ear weight. These crop structures and characteristics are developed after GS31; therefore, environmental conditions during later growth stages (e.g. stem elongation, anthesis and grain filling) may mitigate or exacerbate the level of lodging risk that has developed during tillering, and may have contributed more significantly to lodging susceptibility in 2011 than in 2009. Further investigation is required to determine the relative importance of environmental conditions during different crop stages in the development of lodging risk.

In 2009, the highest yields were obtained in both cultivars in the treatments with low soil $\mathrm{N}$, when residual soil $\mathrm{N}$ was just $60 \mathrm{~kg} \mathrm{Nha}^{-1}$. In 2011, the best yields for both cultivars were achieved when $50 \mathrm{~kg} \mathrm{Nha}^{-1}$ was added at sowing to the $15 \mathrm{~kg} \mathrm{ha}^{-1}$ of soil residual $\mathrm{N}$. The optimum soil + fertiliser $\mathrm{N}$ at sowing under non-limiting conditions for reduced lodging risk at the study location is probably $50-100 \mathrm{~kg} \mathrm{~N} \mathrm{ha}^{-1}$ under fully irrigated conditions, given that the addition of $50 \mathrm{~kg} \mathrm{Nha}^{-1}$ at sowing increased lodging in 2009. This $\mathrm{N}$ level also agrees with that recommended for winter wheat (Berry et al. 2004). It is nevertheless noteworthy that some severely N-stressed treatments were able to recover and achieve high yields when soil $\mathrm{N}$ was just $15 \mathrm{~kg} \mathrm{ha}^{-1}$ at sowing (in 2011) and no further $\mathrm{N}$ was applied until GS31. No previous studies were identified that have achieved near-maximum yields in treatments with such low levels of residual soil N. However, the effect was not consistent across both cultivars, because severe $\mathrm{N}$ stress during tillering did lead to reduced yield in one cultivar in 2011. The existence of cultivar $\times$ management interaction indicates that further study is required into the optimum $\mathrm{N}$-application strategy for specific cultivars.

In applying these results to a commercial production environment, it is important to remember that: (i) the experiments were carried out at a single location on two cultivars; and ( $i$ i) experiments were fully irrigated with overhead sprinklers, conditions that maximised $\mathrm{N}$ availability (and potentially soil $\mathrm{N}$ mineralisation) during vegetative growth and allowed immediate relief of $\mathrm{N}$ stress through small volumes of irrigation following fertiliser application. Thus, further investigation is recommended to ensure the applicability of the results across a wider range of cultivars, soil types, irrigation systems and environments relevant to the furrow-irrigated production systems of subtropical Australia, where regular application of small irrigation volumes is not possible.

Further investigation is also warranted into the lodging susceptibility of a wider range of commercial cultivars relevant to subtropical Australia. Although more severe lodging was observed in Gregory than in Kennedy, the delayed sowing of Kennedy due to rain prevented this assessment from being made under conditions of synchronised anthesis. Such conditions are preferred when assessing cultivars with different phenological development patterns, to ensure that environmental conditions that cause lodging events and influence the development of grain yield are experienced at similar growth stages. Further comparison of these and other cultivars when sown on their optimum sowing dates would be beneficial to growers in identifying the most lodging-resistant cultivars for use in irrigated wheat production. 
When making recommendations to farmers in southern Australia, Lacy and Giblin (2006) recommended 100$120 \mathrm{~kg} \mathrm{Nha}^{-1}$ at sowing, $150-200$ plants $^{-2}$ established, and 500-800 tillers $\mathrm{m}^{-2}$ at GS30 for irrigated wheat production targeting $8 \mathrm{tha}^{-1}$. The seed rates, $\mathrm{N}$ regimes and tiller numbers identified herein for minimising lodging risk while maintaining yield potential were lower than those recommended for southern Australia. Unfortunately, the soil mineral-N content at sowing was $>200 \mathrm{~kg} \mathrm{Nha}^{-1}$ in many production fields during the 2008 season in subtropical Australia when lodging was widespread, because the fields had been prepared for cotton crops that were ultimately not sown (Peake et al. 2014). It is therefore important for the management of lodging to include pre-season testing for soil mineral $\mathrm{N}$ as a prerequisite to developing a management strategy that will minimise lodging risk. Seed rate and tiller number recommendations from southern Australia were also utilised by some growers and agronomists from subtropical Australia in the 2008 season, and it is probable that inappropriate application of these recommendations outside their intended environment contributed to the widespread lodging that was experienced.

\section{Conclusion}

We conclude that the canopy-management techniques of delayed $\mathrm{N}$ application and reduced seeding rate can be used to decrease lodging while maintaining the yield potential of irrigated spring wheat grown in the subtropics. The study also demonstrated a correlation between biomass and canopy development in the vegetative growth phase and lodging risk. This correlation could be used to develop risk-assessment tools for in-season detection of lodging risk, although further investigation is required to determine the relative importance of environmental conditions during different crop stages in the development of lodging risk.

It is important to note that the methodology used in this study (frequent overhead irrigation throughout the season) probably enhanced $\mathrm{N}$ availability in low-N treatments. Further study is recommended to determine the importance of earlyseason irrigation in maintaining $\mathrm{N}$ availability in canopymanaged fields in subtropical regions, in order to assess the applicability of canopy management to furrow-irrigated fields in which irrigation is applied less frequently.

\section{Acknowledgements}

CSIRO and the Grains Research and Development Corporation are gratefully acknowledged for partially funding this study. The assistance of the farm management team at CSIRO is also greatly appreciated.

\section{References}

Baker CJ, Berry PM, Spink JH, Sylvester-Bradley R, Griffin JM, Scott RK, Clare RW (1998) A method for the assessment of the risk of wheat lodging. Journal of Theoretical Biology 194, 587-603. doi:10.1006/ jtbi.1998.0778

Berry P, Griffin J, Sylvester-Bradley R, Scott R, Spink J, Baker C, Clare R (2000) Controlling plant form through husbandry to minimise lodging in wheat. Field Crops Research 67, 59-81. doi:10.1016/S0378-4290(00) 00084-8
Berry PM, Sterling M, Baker CJ, Spink J, Sparkes DL (2003) A calibrated model of wheat lodging compared with field measurements. Agricultural and Forest Meteorology 119, 167-180. doi:10.1016/S0168-1923(03) 00139-4

Berry PM, Sterling M, Spink JH, Baker CJ, Sylvester-Bradley R, Mooney SJ, Tams AR, Ennos AR (2004) Understanding and reducing lodging in cereals. Advances in Agronomy 84, 217-271. doi:10.1016/S0065-2113 (04)84005-7

Bremner PM (1969) Effects of time and rate of nitrogen application on tillering, 'sharp eyespot' (Rhizoctonia solani) and yield in winter wheat. The Journal of Agricultural Science 72, 273-280. doi:10.1017/ S0021859600022188

Crook MJ, Ennos AR (1995) The effect of nitrogen and growth regulators on stem and root characteristics associated with lodging in two cultivars of winter wheat. Journal of Experimental Botany 46, 931-938. doi:10. 1093/jxb/46.8.931

Easson DL, White EM, Pickles SJ (1993) The effects of weather, seed rate and cultivar on lodging and yield in winter wheat. The Journal of Agricultural Science 121, 145-156. doi:10.1017/S0021859600077005

Evans LT (1993) 'Crop evolution, adaptation and yield.' (Cambridge University Press: Cambridge, UK)

Fischer RA (1993) Irrigated spring wheat and timing and amount of nitrogen fertilizer. II. Physiology of grain yield response. Field Crops Research 33, 57-80. doi:10.1016/0378-4290(93)90094-4

Fischer RA, Stapper M (1987) Lodging effects on high-yielding crops of irrigated semidwarf wheat. Field Crops Research 17, 245-258. doi:10.10 16/0378-4290(87)90038-4

Herbert CD (1982) Growth regulation in cereals - chance or design? In 'Chemical manipulation of crop growth and development'. (Ed. JS McLaren) (Butterworth Scientific: London)

Hobbs PR, Sayre KD, Monasterio JIO (1998) 'Increasing wheat yields sustainably through agronomic means.' (International Maize and Wheat Improvement Center: Mexico, DF)

Islam Z, Khan S, Bakht J, Shah WA (2002) Frequency of various N Levels, lodging and seed quality in wheat. Asian Journal of Plant Science 1, 510-512. doi:10.3923/ajps.2002.510.512

Kheiralla KA, Mahdy EE, Dawood RA (1993) Evaluation of some wheat cultivars for traits related to lodging resistance under different levels of nitrogen. Assiut Journal of Agricultural Sciences 24, 257-271.

Knapp JS, Harms CL, Volenec JJ (1987) Growth regulator effects on wheat culm nonstructural and structural carbohydrate and lignin. Crop Science 27, 1201-1205. doi:10.2135/cropsci1987.0011183X00270006 $0022 \mathrm{x}$

Lacy J, Giblin K (2006) Growing eight tonnes per hectare of irrigated wheat in southern NSW. Primefact 197. NSW Department of Primary Industries, Orange, NSW.

Mulder EG (1954) Effect of mineral nutrition on lodging in cereals. Plant and Soil 5, 246-306. doi:10.1007/BF01395900

Peake AS, Huth NI, Carberry PS, Raine SR, Smith RJ (2014) Quantifying potential yield and lodging-related yield gaps for irrigated spring wheat in sub-tropical Australia. Field Crops Research 158, 1-14. doi:10.1016/ j.fcr.2013.12.001

Pinthus MJ (1974) Lodging in wheat, barley, and oats: the phenomenon, its causes, and preventive measures. Advances in Agronomy 25, 209-263. doi:10.1016/S0065-2113(08)60782-8

Rayment GE, Higginson FR (1992) 'Australian laboratory handbook of soil and water chemical methods.' (Inkata Press: Sydney)

Reitz LP, Salmon SC (1968) Origin, history, and use of Norin 10 wheat. Crop Science 8, 686-689. doi:10.2135/cropsci1968.0011183X0008000 $60014 \mathrm{x}$

Sparkes DL, King M (2008) Disentangling the effects of PAR and R:FR on lodging-associated characters of wheat (Triticum aestivum). Annals of Applied Biology 152, 1-9. doi:10.1111/j.1744-7348.2007.00184.x 
Sparkes DL, Berry P, King M (2008) Effects of shade on root characters associated with lodging in wheat (Triticum aestivum). Annals of Applied Biology 152, 389-395. doi:10.1111/j.1744-7348.2008.00230.x

Spink JH, Foulkes MJ, Gay A, Bryson R, Berry PM, Sylvester-Bradley R, Semere T, Clare RW, Scott RK, Kettlewell PS, Russell G(2000) Reducing winter wheat production costs through crop intelligence information on variety and sowing date, rotational position, and canopy management in relation to drought and disease control. Project Report 235, Home-Grown Cereals Authority, London.

Stapper M, Fischer RA (1990a) Genotype, sowing date and plant spacing influence on high-yielding irrigated wheat in southern New South Wales. II. Growth, yield and nitrogen use. Australian Journal of Agricultural Research 41, 1021-1041. doi:10.1071/AR9901021

Stapper M, Fischer RA (1990b) Genotype, sowing date and plant spacing influence on high-yielding irrigated wheat in southern New South Wales. III. Potential yields and optimum flowering dates. Australian Journal of Agricultural Research 41, 1043-1056. doi:10.1071/AR9901043

Sylvester-Bradley R, Scott R, Stokes D, Clare R (1997) The significance of crop canopies for N nutrition. Aspects of Applied Biology 50, 103-116.

Sylvester-Bradley R, Spink J, Foulkes M, Bryson R, Scott R, Stokes D, King J, Parish D, Paveley N, Clare R (2000) Sector challenge project-canopy management in practice. In 'Proceedings HGCA 2000 Crop Management into the Millennium Conference'. (Home-Grown Cereals Authority: London)

Tottman DR (1987) The decimal code for the growth stages of cereals, with illustrations. Annals of Applied Biology 110, 441-454. doi:10.1111/ j.1744-7348.1987.tb03275.x

Tripathi SC, Sayre KD, Kaul JN, Narang RS (2003) Growth and morphology of spring wheat (Triticum aestivum L.) culms and their association with lodging: effects of genotypes, $\mathrm{N}$ levels and ethephon. Field Crops Research 84, 271-290. doi:10.1016/S0378-4290(03)00095-9

Tripathi SC, Sayre KD, Kaul JN (2005) Planting systems on lodging behavior, yield components, and yield of irrigated spring bread wheat. Crop Science 45, 1448-1455. doi:10.2135/cropsci2003-714

Webster JR, Jackson LF (1993) Management practices to reduce lodging and maximize grain yield and protein content of fall-sown irrigated hard red spring wheat. Field Crops Research 33, 249-259. doi:10.1016/03784290(93)90083-Y

Widdowson F, Penny A, Williams R (1961) Autumn nitrogen for winter wheat. The Journal of Agricultural Science 57, 329-334. doi:10.1017/S0 021859600049297

Zadoks JC, Chang TT, Konzak CF (1974) A decimal code for the growth stages of cereals. Weed Research 14, 415-421. doi:10.1111/j.1365-3180. 1974.tb01084.x 